\title{
FOTOGRAFIA DE MODA: ANÁLISE SEMIÓTICA DAS CAMPANHAS DAS MARCAS ELLUS E RIACHUELO
}

Larissa Crepaldi Trindade, Mariangela Fazano Amendola, Camila Rotta

Universidade do Oeste Paulista - UNOESTE, Curso de Publicidade e Propaganda, Presidente Prudente, SP. E-mail: larissa@unoeste.br

\section{RESUMO}

O presente estudo tem como corpus de análise a fotografia de moda brasileira das campanhas publicitárias das marcas Ellus e Riachuelo. A pesquisa analisou as fotografias das capas dos catálogos das respectivas marcas, de acordo com a concepção semiótica de Roland Barthes. Foram observados os conteúdos que envolvem a fotografia (operator, spectrum e spectator), os métodos de conotação (trucagem, pose, objetos, fotogenia, estética e sintaxe) e o interesse cultural e sentimental pela fotografia (studium e punctun).

Palavras-chave: Fotografia de moda; Marca; Semiótica; Roland Barthes.

\begin{abstract}
This study is analysis of corpus Brazilian fashion photography of advertising campaigns of Ellus and Riachuelo marks. The research analyzed the photos of the covers of catalogs of their brands, according to the theoretical concept of Roland Barthes. The contents were observed involving the photo (operator, spectrum and spectator), the connotation methods (trickery, pose, objects, photogenic, aesthetics and syntax) and the cultural and sentimental interest in photography (studium and punctun).
\end{abstract}

Keywords: Fashion photography; Brand; semiotics; Roland Barthes 


\section{ASPECTOS INTRODUTÓRIOS}

O corpus desta análise é constituído pelas fotografias das capas dos catálogos de inverno 2013, das marcas brasileiras de confecção de roupa feminina, Ellus e Riachuelo.

As duas marcas brasileiras são distintas no que se refere às características de produção, valor do produto e conceito de marca. Perez (2004), afirma que toda marca atribui um status de caráter diferenciado, pois cada uma produz suas próprias significações de acordo com determinado locus social.

Segundo o site institucional da Ellus (2014), a marca foi fundada em 1972 e sempre buscou uma imagem lúdica e conceitual, se mostrando sofisticada e com atitude rock'n'roll.

A Riachuelo, de acordo com seu site oficial (2014), por sua vez, expressa o conceito de fast fashion, característica que demonstra agilidade na produção e na distribuição das coleções.

O interesse em desvendar a fotografia dessas campanhas se dá no levantamento de como os elementos que a constituem, contribuem com a construção do imaginário. Elas influenciam a constituição do imaginário de um público-alvo pretendido, auxiliando assim os estudos da área da publicidade, tendo como objeto de estudo a fotografia de moda.

Para identificar os aspectos técnicos, estéticos e comportamentais das fotos das respectivas marcas, será utilizada a teoria dos signos sob as perspectivas propostas por Roland Barthes.

O objetivo da análise das fotografias das campanhas, apresenta viés nos aspectos técnicos da fotografia, como enquadramento, iluminação e cor. Aspectos estéticos da moda, como produção de figurino, tendências, maquiagem, expressão facial e postura corporal. E aspectos de composição dos objetos (cenografia/direção de arte). Segundo Codato e Lopes (2010) Os profissionais da área de fotografia, moda e publicidade começaram a se interessar pelos estudos semiológicos desenvolvidos pelo escritor, filósofo e semiólogo, Roland Barthes, cuja aplicação nesse campo torna-se cada vez mais nítida e constante. A utilização da metodologia semiótica neste projeto é essencial, pois de acordo com Codato e Lopes (2010), para compreender os sentidos da moda, devemos estudar suas linguagens e os usos sociais do corpo e do vestuário como um todo.

\section{MÉTODO DE ANÁLISE}

O método utilizado é a teoria semiótica, que considera a imagem como signo. Essa análise é de origem barthesiana que segundo Souza e Custódio (2005) consiste em tentar estabelecer um paralelo entre dois planos: o da expressão das fotografias (o que ela mostra) e seu conteúdo (o que 
ela significa). Tanto quanto a realidade exterior a que ela faz referência (significante) e o conteúdo material da imagem (significado).

Barthes (1984) afirma que uma foto pode ser objeto de três intenções: fazer (Operator), suportar (Spectrum) e olhar (Spectator). O Operator é o fotógrafo, aquele que reproduz a imagem. O Spectrum é o ser fotografado, podendo ser uma pessoa ou um objeto. E o Spectator é quem recebe a mensagem.

Em síntese, Barthes (1984) nos apresenta dois tipos de mensagens existentes na fotografia artística (publicitária): a mensagem denotada e a mensagem conotada. A mensagem denotada é a representação pura da imagem representada pelos objetos da cena. Segundo Barthes (1984) o nível denotativo da imagem inclui a percepção e o conhecimento cultural do receptor. A mensagem conotada representa os aspectos simbólicos da imagem.

Para analisar a conotação da imagem fotográfica faz-se necessário estudar os seus métodos, já que o segundo sentido da mensagem elabora-se, segundo Barthes (1984) os diferentes níveis de produção da fotografia (escolha, processamento técnico, enquadramento, diagramação).

Conforme nos explica o autor, nos três primeiros procedimentos de conotação da imagem fotográfica (trucagem, pose, objetos), a conotação é produzida por uma modificação da própria mensagem denotada. No segundo grupo de elementos encontram-se os processos de conotação (fotogenia, esteticismo e sintaxe).

As fotografias a serem analisadas são capas das campanhas das marcas selecionadas, pois possuem nelas uma função imagem-texto, onde o texto representa o título/nome da marca e, no caso de uma das fotografias, assinalam coleções que serão lançadas.

A estrutura que nos interessa neste trabalho é a icônica e a tecnológica, para falar da imagem de determinado traje, é necessário falar dele como objeto concreto. A semiologia da moda, para Barthes (2009), está inteiramente voltada para um conjunto de representações coletivas.

Segundo Barthes (2009), é a partir da linguagem da moda que ela própria se constrói (tendências de cor, textura, tecido, modelagem, formas), determinando suas significações. 


\section{ANÁLISE DAS FOTOGRAFIAS DE MODA DAS MARCAS ELLUS E RIACHUELO}

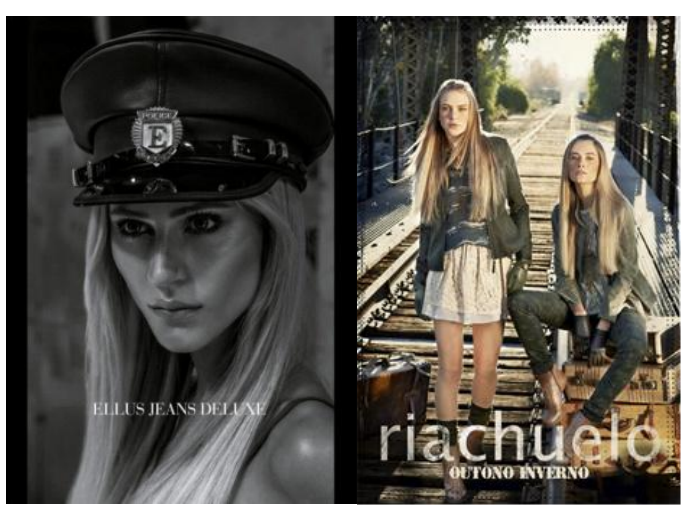

FIGURAS 01e 02. Capa dos Catálogos 2013 das marcas

Fonte: Sites institucionais da Ellus e da Riachuelo, 2014.

A primeira fotografia a ser analisada (figura 01), foi extraída do catálogo de inverno 2013 da marca Ellus. Iniciaremos a análise com a identificação dos objetos nesta fotografia. O Operator dessa imagem fotográfica envolve uma equipe composta por: fotógrafo (Jacques Dequeker), assistente, diretor de arte, maquiador e stylist. O ser fotografado, o Spectrum, é representado por uma modelo brasileira chamada Alicia Kuczman (na época em que a fotografia foi clicada, a modelo foi considerada uma revelação no mundo da moda). Podemos dizer que o Spectator representa o público-alvo da marca Ellus, representado pelas jovens e mulheres de classes A e B. Para formação de uma imagem de marca direcionada a classe alta, se faz necessário o uso de supermodelos e fotógrafos famosos no segmento de moda.

O elemento que desperta o studium está presente na disposição dos objetos em primeiro plano: o chapéu que a modelo veste atrai esteticamente a foto. As características de fotogenia da fotografia que manifesta sentimento no spectator; é sua falta de cor e a pose da modelo que desperta sensualidade. O punctun, que atinge de forma profunda e sentimental um mistério no contexto da foto.

A mensagem denotada dessa fotografia nos mostra uma jovem loira com um chapéu de policial. Já a conotação se encontra no momento em que percebemos que esta jovem loira é policial.

O efeito preto e branco da fotografia é uma técnica de impressão é a cor utilizada para conotar a sofisticação da marca. A iluminação é de cinema (luz contínua), vinda de cima como se fosse uma lâmpada presente na locação externa, que representa o ambiente interno de uma 
delegacia de polícia antiga. Outro tipo de iluminação utilizada foi o flash de preenchimento, com o objetivo de tornar nítido o rosto da modelo. O ângulo da foto é de 45ํ e a posição da câmera está um pouco abaixo da modelo, para conotar a ideia de poder, superioridade.

Sua maquiagem é bem marcada, destacando e iluminando os pontos fortes do rosto da modelo (maxilar, nariz, olhar). Os olhos são maquiados levemente somente com rímel, dando ar de naturalidade. A pose da modelo sugere um ar superior, como se ela tivesse algum posto importante dentro da polícia. A Ellus usufrui dessas particularidades devido a sua personalidade de atitude rock'n'roll e urbana underground.

A única comunicação verbal presente na imagem é o nome da marca. Muito comum nesse segmento destinado para esse público-alvo, onde a principal informação é lúdica e conceitual.

O plano da foto é fechado, dando close no rosto da modelo e não podemos identificar o produto nela. Na fotografia a indumentária está presente somente no chapéu, mas o mesmo não faz parte da coleção. Ele representa um ícone do estilo militar, inserindo assim a simbologia de tendência da estação.

Com a análise fotográfica realizada, podemos inferir que a Ellus é uma marca que vende uma ideia de sofisticação e poder, pois seu produto não está exposto na foto, mas sim uma atitude, uma maneira de ser, um estilo underground, que acima de tudo, no contexto analisado, pretende refletir o que está na moda.

A outra fotografia a ser analisada (figura 02) é a capa do catálogo da Campanha de inverno 2013 da Riachuelo.

Para Barthes (1990) a fotografia publicitária é intencional, o Operator da fotografia envolve uma equipe de especialistas: fotógrafo, assistente, diretor de arte, maquiador e stylist. A imagem fotográfica da Riachuelo é composta por dois Spectrum; duas modelos não identificadas. O Spectator representa o público-alvo da marca, constituído, principalmente, pelas jovens mulheres da classe $\mathrm{C}$.

O studium apresentado nessa fotografia é o próprio sujeito composto nela, ou seja, as modelos. Os elementos que despertam o punctun são: o cenário e seus objetos, o que leva o spectator a uma ideia de continuidade dessa fotografia, remetendo à viagem.

A mensagem denotada nos mostra duas jovens mulheres loiras em um trilho de trem, apoiadas em malas sobrepostas. A primeira conotação se encontra além da cena, onde imagina-se 
um trem que está a caminho, onde as duas mulheres irão embarcar. A pose das modelos sugere certa atitude, olhando diretamente para a objetiva da câmera.

Outra conotação encontrada na fotografia em seu conjunto, devido ao local onde a fotografia foi tirada (trilho do trem), é o convite a embarcar na moda da Riachuelo.

A terceira conotação se encontra nos objetos presentes na fotografia, as malas, onde instigam volume de compra, pois a marca é caracterizada como sendo eclética e com baixo valor, fazendo com que o consumidor possa comprar mais peças de roupa. Por se tratar de uma campanha de outono-inverno optou-se por tons terrosos, puxados para o bege e verde musgo. A iluminação é feita de forma mais natural possível, com um contra luz solar e uma iluminação direta no lado esquerdo da imagem. Segundo Guran (1992) enquanto a luz direta tende a estabelecer uma hierarquia de valores a partir de si, destacando os elementos pela sua incidência, a luz difusa se derrama por igual sobre a cena, permitindo que outros fatores de valorização do conteúdo ganhem peso na composição.

A campanha demonstra que pretende inteirar-se no mercado do segmento fast fashion, expressando em tipografia caixa alta o nome da marca e a indicação da estação. De acordo com Villaça e Castilho (2006, p. 137) "consumir o produto é uma consequência da estratégia da marca que promete a realização dos desejos inconscientes do consumidor."

A estratégia mais importante da marca Riachuelo reflete o hiper consumo da atualidade, chamada fast fashion, que, segundo Delgado (2008), troca grande parte das mercadorias das lojas a cada quinzena, contando com um planejamento da logística mundial e da criação acelerada de novos produtos.

A campanha da Riachuelo enfatiza as roupas na composição da imagem, isto pode ser considerado um apelo comercial e não conceitual. Pode-se observar as tendências apresentadas pelo SPFW (2013), na vestimenta das modelos, que por sua vez são compostas por renda, couro, luvas e o tecido verde-musgo militar, que representa, como já citado as tendências da moda do inverno 2013.

\section{CONSIDERAÇÕES FINAIS}

A presente pesquisa demonstrou, por meio de estudos sobre fotografia, moda, semiologia e publicidade, que as duas marcas do segmento de moda feminina analisadas, são distintas em diversos aspectos. 
As duas marcas possuem personalidades completamente diferentes. A constatação feita a partir desta análise nos apresenta a oposição de sentidos que a conotação de cada discurso fotográfico oferece. Assim como; o plano das fotografias, onde em Ellus é fechada no rosto da modelo e em Riachuelo o plano é aberto; a coloração, onde em Ellus há ausência de cor e em Riachuelo não; a quantidade dos objetos presentes na foto, Ellus apresenta somente um objeto que é adorno, e Riachuelo uma série de objetos de cena; a expressão facial das modelos e enquanto Ellus possui uma imagem conceitual, onde são apresentadas tendências abstratas (como o chapéu), a Riachuelo apresenta uma imagem comercial, expressando uma moda pronta a ser consumida. Para concluir, podemos dizer que a Ellus procura ser a inspiração para todos, já a Riachuelo procura inspirar-se no que está na moda.

Por fim podemos esperar, com este trabalho, ter contribuído para o entendimento sobre as diferenças das fotografias das campanhas na construção da imagem de uma marca. E como as técnicas fotográficas e as conotações que delas emanam, constatadas por meio de reflexões teóricas embasadas nas propostas de Roland Barthes, auxiliam na busca dos significados imanentes do discurso proposto.

\section{REFERÊNCIAS}

BARTHES, Roland. A câmara clara. Trad. Júlio Castanon Gumarães. Rio de Janeiro: Ed. Nova Fronteira, 1984.

. Imagem e Moda. Trad. Ivone C. Benedetti. São Paulo: Ed. Martins Fontes, 2005.

. O óbvio e o obtuso. Trad. Léa Novaes. Rio de Janeiro: Ed. Nova Fronteira, 1990.

. Sistema da Moda. Trad. Ivone C. Benedetti. São Paulo: Ed. Martins Fontes, 2009.

CODATO, Henrique; LOPES, Flor. A semiologia e semiótica como ferramentas metodológicas. In: DUARTE, Jorge \& Antonio BARROS, A. Métodos e técnicas de pesquisa em comunicação. São Paulo: Ed. Atlas, 2010.

DELGADO, Daniela. Fast fashion: estratégia para conquista do mercado Globalizado. In Modapalavra e-periódico. CEART - Florianópolis, 2008.

ELLUS. Site institucional, 2014. Disponível em <www.ellus.com>. Acesso em: 21 out 2014.

FLUSSER, Vilém. Filosofia da Caixa Preta: Ensaios para uma futura filosofia da fotografia. São Paulo: Ed. Hucitec, 1985. 
GURAN, Milton. Linguagem fotográfica e informação. Rio de Janeiro: Ed. Rio Fundo LTDA, 1992.

ITTEN, Johannes. The art of color. New York: John Wiley \& Sons, Inc., 1976.

LIMA, Ivan. A fotografia é a sua linguagem. Rio de Janeiro: Ed. Espaço e Tempo, 1988.

LIPOVESTKY ; ROUX, Elyette. O luxo eterno: da idade do sagrado ao tempo das marcas. Trad. Maria Lúcia Machado. São Paulo: Ed. Companhia das letras, 2008.

MARTINS, Nelson. Fotografia: da analógica à digital. Rio de Janeiro: Ed. Senac, 2010.

PEREZ, Clotilde. Signos da marca: expressividade e sensorialidade. São Paulo: Ed. Thomson, 2004.

PINHO, José. O poder das marcas. São Paulo: Ed. Summus Editorial, 1996.

SOUZA, Valdete; CUSTÓDIO, José. Fotografia: Meio e Linguagem dentro da Moda. Londrina-PR: Ed. Discursos fotográficos, 2005.

RIACHUELO. Site institucional, 2014. Disponível em <www.riachuelo.com.br>. Acesso em: 23 out 2014.

VILLAÇA, Nízia e CASTILHO, Kátia. Plugados na Moda. São Paulo:Ed. Anhe RODRIGUES 2007. 